\title{
Para quem escreve uma criança?
}

PASTORELLO, LUCila ${ }^{1}$

\section{RESUMO}

Considerando a leitura e a escrita como práticas sócias da linguagem, este texto pretende focalizar o endereçamento do texto escrito pela criança. A proposta é realizar um exercício reflexivo a partir dos índices de subjetividade observados em textos escritos por uma mesma criança em diferentes momentos do processo de apropriação da escrita. É possível observar desde os primeiros textos a presença de um interlocutor na escrita da criança, uma marca de alteridade que confere sentido à escrita.

Leitura e escrita. Subjetividade. Escrito.

\section{To whom do a child writes?}

\begin{abstract}
Considering the reading and writing associal practices of the language, the subject intends to focus on the addressing of the text written by the child. The proposal is to do a reflexive exercise from the subjective indexes seen in texts written by the same child in different moments of the process of writing appropriation. It is possible to observe from the first texts the presence of a interlocutor in the child writing, a mark of otherness that provides sense to the writing.
\end{abstract}

Reading and writing. Subjective. Write.

\section{¿Para qué sirve un niño?}

\section{RESUMEN}

Considerando la lectura y la escritura como prácticas sociales del lenguaje, este texto intenta enfocarse en el direccionamento del texto escrito por niños. La propuesta es llevar a cabo un ejercicio reflexivo basado en los índices de subjetividad observados en textos escritos por uno mismo niño en diferentes momentos del proceso de apropiación de la escrita. Es posible observar desde

\footnotetext{
1 Doutora em Educação pela USP (2010), fonoaudiólogo da formação de professores El da Secretaria Municipal de Educação. E-mail: lucilapastorello@gmail.com Lattes: http://lattes.cnpq.br/3276503795042757.

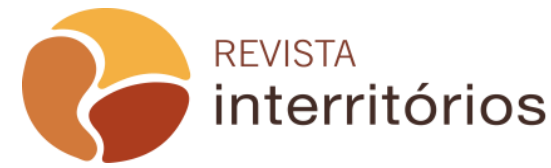


los primeros textos la presencia de un interlocutor en la escritura del niño, una marca de alteridad que le dio un significado a la escrita.

Lectura y escritura. Subjetividad. Escritura.

\section{A cosa serve un bambino?}

\section{SINTESE}

Considerando la lettura e la scrittura come pratiche sociali del linguaggio, questo testo cerca di concentrarsi sulla direzione del testo scritto dai bambini. La proposta è di svolgere un esercizio riflessivo basato sugli indici di soggettività osservati nei testi scritti dallo stesso bambino in momenti diversi del processo di appropriazione di quello scritto. È possibile osservare dai primi testi la presenza di un interlocutore nella scrittura del bambino, un segno di alterità che ha dato il significato scritto.

\section{Linguaggio. Scrittura. Lettura.}

\section{INTRODUÇÃO}

Pensar a leitura e a escrita como práticas socioculturais da linguagem permite tratá-las em seu aspecto enunciativo. A partir de Benveniste (1976) é possível identificar os processos de linguagem como atrelados à subjetividade. O conceito de enunciação proposto pelo autor abre espaço para estudar as condições de produção do discurso e não apenas o escrito, o falado. Importa o enunciado, mas também quem diz, quando, como, para quem, onde acontece o discurso.

Nesta direção, o objetivo aqui é discutir aspectos da entrada da criança na escrita, focalizando o endereçamento da escrita: para quem escreve a criança que entra no mundo letrado? O que mobiliza este questionamento é a experiência a partir da clínica fonoaudiológica com crianças que tropeçam no aprendizado da escrita. Em meus atendimentos me deparo com crianças com as quais algo não vai bem no campo da linguagem. Muitas delas perguntam "quem vai ler o que escrevo?" ou "por que eu tenho que escrever de novo se você já entendeu o que escrevi?" e finalmente "para que escrever?"

Para esboçar uma resposta ao questionamento enunciado, trago produções de escrita de uma criança dos 6, 4 aos 7.,8 anos, em processo normal de apropriação da escrita, sem queixas. Como suporte teórico tomo elementos da constituição subjetiva oferecidos pela psicanálise, especialmente a partir da leitura de Lacan; a proposta de Lemos (2002) a respeito das diferentes posições da criança em relação ao outro na aquisição/apropriação da linguagem e as 
contribuições de Riolfi (2003) e Belintane (2006) a propósito das marcas singulares nas produções de linguagem da criança.

Em um primeiro momento apresento brevemente os posicionamentos teóricos com os quais identifico minha argumentação; em seguida apresento as produções da criança, localizando condições de produção do material escrito e finalmente traço considerações que possa, a partir da teoria e da análise do material, ao menos ensaiar uma resposta, mesmo que provisória, ao questionamento complexo anunciado no título deste trabalho.

Apresento-me no difícil terreno da interdisciplinaridade; não pretendo definir modos de relações entre os campos, quais sejam a aquisição linguagem, a psicanálise e a clínica fonoaudiológica, mas ensaiar possibilidades de articular conhecimentos e novas perspectivas para encarar antigas questões, produzindo texto pinçando fios de diferentes áreas do saber.

\section{Estudar a entrada da criança na escrita}

Os estudos sobre a entrada da criança na escrita apresentam-se marcados por vertentes teóricas que privilegiam um ou outro aspecto da escrita, mas essencialmente diferem quanto à concepção de sujeito em questão. É possível observar nos estudos na linha da psicologia cognitiva, que toda a armação teórica pressupõe um sujeito que aprende ou se desenvolve a partir da atualização de esquemas mentais, mais ou menos inatos, que se opera via ação sobre o mundo (de relações e objetos de conhecimento); nos estudos de orientação construtivista, que marcam de maneira forte os atuais trabalhos em aquisição de linguagem escrita, especialmente a partir dos trabalhos de Emília Ferreiro, a criança é vista como ativa no processo.

A noção de desenvolvimento e etapas a serem percorridas pela criança, no entanto, não aborda a estruturação subjetiva. Neste modo de pensar a linguagem o sujeito é aquele que vai se apropriando progressivamente do objeto de conhecimento socialmente estruturado: a linguagem. Mesmo nos trabalhos de orientação sócio interacionista, influenciados especialmente pelos trabalhos de Vygotsky, em que pese o papel do outro na construção do conhecimento e uma orientação do intersubjetivo para a organização intrasubjetiva, a aquisição ou o desenvolvimento é visto como orientado temporalmente, ou seja, a partir da experiência com o outro a criança vai adquirir, em etapas, o domínio da linguagem.

No presente texto parto de uma perspectiva teórica que considera apropriação da língua materna, seja oral ou escrita, como atrelada à 
subjetividade, e não suportada por fases de desenvolvimento que se substituem cronologicamente. Assim como comenta Belintane:

\begin{abstract}
Assumimos que o que se constrói no início, a base infantil, o núcleo parental, a linguagem fundamental, constitui-se de marcas indeletáveis que funcionam ativamente em todas as fases do indivíduo. Aprender não é apenas saltar de um estado de menos conhecimento para outro mais elevado; se levarmos em conta a dimensão do inconsciente, a emergência subjetiva, aprender é movimentar uma subjetividade capaz de constituir um interjogo significante e significativo, que ao passar pelas dimensões da singularidade, do inconsciente é capaz de arejar a linguagem e as impressões que recebemos do outro e produzir nelas algum vazio operante. (BELINTANE, 2006, p. 74)
\end{abstract}

Também De Lemos (2002), reconhecendo a ineficácia das abordagens psicolinguísticas no campo da Aquisição da Linguagem para dar conta da complexidade da análise da fala da criança, que não conseguem lidar com a falta de regularidade dos processos descritos pela teoria, propõe considerar mudanças de posição em uma estrutura. Para escapar de uma visão desenvolvimentista - conforme a autora, por ela mesma defendida há anos atrás - de Lemos encara a fala da criança como enigma, um desafio ao pesquisador, e a partir da leitura de Lacan, sugere que a criança manifesta em sua fala diferentes posições em relação ao outro. A autora afirma estas posições não dizem respeito a etapas cronológicas, mas à constituição subjetiva e que não há superação de uma ou outra. Aqui, sujeito é tomado na concepção psicanalítica, como efeito de linguagem. Nas palavras da autora:

\begin{abstract}
Foi, em um segundo momento, que esta mudança foi definida como mudança de posição em uma estrutura, no sentido que não há superação de nenhuma das três posições, mas uma relação que se manifesta, na primeira posição, pela dominância da fala do outro, na segunda posição, pela dominância do funcionamento da língua e, na terceira posição, pela dominância da relação do sujeito com sua própria fala .

Seria na terceira posição que a criança, enquanto sujeito falante, se dividiria entre aquele que escuta a própria fala, sendo capaz de retomá-la e reconhecer a diferença entre sua fala e a fala do outro, assim como entre a instância subjetiva que fala e a instância subjetiva que escuta de um lugar outro.(LEMOS, 2002, 56)
\end{abstract}

Seguindo este pensamento, na primeira posição é possível encontrar uma alienação na fala do outro: a fala da criança aparece com marcas de fragmentação (em que as repetições de fragmentos da fala do outro são uma constante) e dependência (da interpretação do outro). Não há, no entanto, uma 
coincidência da fala do outro e da criança: analisando trechos de diálogos entre mãe e criança, de Lemos chama a atenção para a escuta da fala da mãe na fala da criança. Poderíamos dizer que, embora retome fragmentos da fala do outro, a fala da criança é endereçada e a interpretação da mãe é "autorizada" ou "interditada" 2; é justamente neste endereçamento e autorização/interdição da interpretação do outro que emerge o sujeito, ou com explica a autora:

Se o pólo dominante ou convergente na primeira posição é o outro, as relações entre os significantes que vêm do outro dão a ver o funcionamento da língua e um processo de subjetivação por ele regido, isto é que aponta par um sujeito emergente no intervalo entre os significantes do outro. (LEMOS, 2002, p. 58).

Na segunda posição não é fragmentação ou dependência que dão o tom, mas o aparecimento de erros, paralelismos e de interpretações idiossincráticas do funcionamento da língua; a língua é o polo dominante; o sujeito está alienado no próprio movimento da língua.

Já na terceira posição a criança reconhece a própria fala e o erro, atua para corrigir-se, ou nas palavras de De Lemos são observados fenômenos como pausas, reformulações, correções, convocadas ou não pela reação direta ou indireta do interlocutor. Nesta posição há uma criança que fala e que escuta sua própria produção e pode ler os efeitos de sua fala no outro. Embora De Lemos não nos faça esta conclusão, ouso sugerir que nesta posição, a criança fala para um outro que é ao mesmo tempo semelhante e distinto de si, e sua fala é regulada pela língua sim, mas instanciada pelo outro, a quem a fala é endereçada.

Os conceitos trabalhados pela autora são interessantes para pensar modos de funcionamento da linguagem da criança, alternativos ao pensamento em etapas e fases. No entanto chamo a atenção para uma ocorrência no texto em questão: ao discorrer sobre as posições a autora usa exemplos de fragmentos de fala de crianças em que há uma correspondência entre as posições na estrutura e a idade. ${ }^{3}$ É certo que existe uma linha do tempo em que as posições tomam lugar pela primeira vez, mas também é preciso observar que estas posições são colocadas em jogo durante toda a vida do sujeito, e o modo como os exemplos são dados no texto podem levar a uma leitura equivocada, como se as posições em relação ao outro/Outro estivessem em uma relação de progressão cronológica, o que nos remeteria a um golpe de vista

${ }^{2}$ Termos meus, a partir da leitura do texto.

${ }^{3}$ Para exemplificar a primeira posição a autora toma fragmentos de crianças com 1 ano e 2 meses e 1 ano e 8 meses; para exemplificar a segunda posição as idades variam entre 2 anos 7 meses a 2 anos e 11 meses; e na terceira posição 4 anos a 4 anos e 2 meses. 
desenvolvimentista. É claro que "para bom entendedor, meia palavra basta", mas devemos lembrar que os textos na área de Aquisição da Linguagem são bastante comuns em leituras interdisciplinares, que muitas vezes não partilham do mesmo horizonte discursivo e conceitual.

Podemos atualizar este modelo para estudar a entrada da criança na escrita 4 : a criança pode se posicionar de diferentes modos na relação com 0 outro, com a língua e com suas próprias produções. Mas o que a faz engatar-se ao outro e endereçar-lhe suas produções gráficas? o que a faz colar/descolar no outro? Penso que é possível continuar o exercício, trazendo aspectos da entrada da criança na linguagem oral e a noção de alteridade circulante nos trabalhos de Lacan para então entender o que move a criança a escrever.

O endereçamento da escrita envolve a oferta de uma produção gráfica ao outro e está ligada a possibilidade de leitura do outro. A criança "escreve" porque alguém a lê. $\mathrm{O}$ gesto de oferta pode funcionar, em um primeiro momento, mais do que a produção em si. Assim como o bebê oferece seu choro e balbucio à mãe, que recorta e marca a massa sonora, imprimindo linguagem, podemos pensar que oferecer à mãe, familiares e professoras as produções gráficas da criança pequena, ainda não letrada, é parte importante da história da criança na escrita.

Ao reconhecer seus traços como produções e dar-se a ler ao outro, a criança se engata no jogo dialético, de idas e voltas com o outro Se observarmos a criança pequena neste gesto de oferta, perceberemos que a criança não apenas oferece suas produções, mas observa o deciframento do outro; não raro a criança negocia com o outro a interpretação, aceitando, refutando, fazendo e observando marcas. O que a criança escreve ainda não é legível, mas poderíamos dizer, "leiturável". Este primeiro passo de oferta do material gráfico só é possível para a criança que reconhece, em primeiro lugar, a demanda do outro em relação à suas produções e em segundo lugar, a possibilidade de idas e voltas sobre a produção, envolvendo estar no campo do Outro pela língua escrita.

A demanda do outro, que cria o espaço primeiro para a resposta da criança, é que se pode ver nos comentários que os adultos (e mesmo outras crianças) fazem frente a algum "gesto de escritor/leitor" que a criança pequena relacionado de alguma forma com a escrita. Se a criança pega um lápis o outro diz: "Olha só!!!! Você vai escrever!!!" Quando a criança folheia um livro: "Vamos ler esta história?". É este investimento do outro no escritor/leitor potencial que cria a possibilidade de resposta da criança, que então engata no jogo de dar e receber que fará corpo na escrita.

\footnotetext{
${ }^{4} \mathrm{~A}$ escrita tomada em questão neste texto é a escrita alfabética,
} 
Estas primeiras atividades estão no campo da brincadeira, pois ao adulto que faz comentários sobre os gestos da criança sabe que, de fato, a criança ainda não escreve. No entanto o adulto supõe e solicita um ser escrevente, assim como a mãe do bebezinho supõe um falante a partir de vocalizações.

Pensando desta forma, é a partir do discurso do outro que a criança se lança na possibilidade de traçar marcas no papel; o que ocorre na criança antes de dominar a escrita não é apenas o exercício de habilidades motoras cognitivosimbólicas ou grafo-fônicas. Trata-se de exercitar-se na possibilidade e no próprio funcionamento da escrita. O "balbucio- escrito" é normalmente constituído por traços, garatujas, letras, quase letras. Como assinala Bosco ( 1999) o amalgama de letras-desenho que produz a criança pequena não advém de uma dificuldade da criança em perceber texto imagético e verbal, como defende Emília Ferreiro, mas trata-se justamente de ensaiar, experimentar ciframentos, compondo textos em algo que poderíamos chamar de "holografismos", material que condensa sentenças e até pequenas narrativas em um complexo semiótico formado por desenho-letra-grafismos.

Esta composição é submetida ao olhar do outro, que ao mesmo tempo se regozija por receber o que pediu (o material da criança), como representante da língua faz circular o Outro que incide na interpretação que é dada/negociada sobre a produção infantil. É porque o outro (mãe, pai, tio, irmão mais velho, professora...) Ihe pede que a criança escreve. Esta escrita é ofertada na possibilidade de funcionar como resposta e como oferta de um corpo a ser marcado. É no olhar e na voz do outro que a criança pode então se haver com a língua, com o Outro para então experimentar a difícil articulação entre a subjetividade e a singularidade, a expressão daquilo que de fato é seu na possibilidade que o Outro concede uma brecha.

Mas escrever não é o mesmo que falar. Perde-se o corpo na escrita; perde-se a voz, a entonação a enunciação. O sujeito tem que se haver com o enunciado. Além disso sua marca fica, testemunha duradoura. Para aprender a escrever a criança precisa dar passos mais largos na constituição subjetiva e na apropriação da linguagem e dos mecanismos da língua. Não é tarefa para meses e sim para anos, ou para uma vida toda.

Para escrever, mais do que traçar letras segundo a língua determina, é preciso fazer texto, tornar-se autor, de forma que aquilo que é dito/escrito carregue marcas singulares Nazar (2006) a respeito da escrita literária, argumenta que o que faz o autor é seu estilo, a apresentação de suas letras. É preciso, portanto que aquele que escreve se engate, na dialética da relação com o outro, numa posição que lhe permita dar a ler suas letras, sabendo que o Outro Ihe cobrará a responsabilidade pelo escrito. Em certa medida esta noção de autoria faz lembrar o conceito introduzido por Foucault em " O que é um autor?" (1969/1992) Para Foucault, a função autor é a que permite à cultura identificar 
traços singulares daquele que escreve e ao mesmo tempo inseri-lo em uma posição de responsabilidade por aquilo que escreve ${ }^{5}$.

Testemunhar os momentos de indícios de autoria na fala/escrita de uma criança pode ser uma maneira interessante de entender os mecanismos que permeiam as relações entre produção da linguagem e da subjetividade. É o que faz Riolfi (2003) ao nos mostrar como os equívocos na fala de uma criança em duas cenas, em distintos momentos cronológicos, podem nos falar do erro não como desvio, mas exatamente como uma marca singular, em que se vislumbra a função de autor. Nas palavras de Riolfi:

O que une tais falas é o fato que dão a ver muito claramente a presentificação da singularidade da criança, que, na primeira cena comparece quase por acidente, enquanto na segunda, já de modo bastante deliberado. Entre elas localiza-se uma passagem bastante importante; se na primeira L. se equivoca, na Segunda joga com o equívoco e faz brilhar uma interpretação tão singular que merece o comentário de que só poderia ter sido ela quem disse uma coisa dessas. (RIOLFI, 2003, p. 221)

Riolfi nos lembra de que a construção da subjetividade não vem de graça, mas é construída a partir de determinadas operações que determinam desde o equívoco como manifestação de uma posição referente à língua até o uso do equívoco e das aberturas de sentido para manifestação da singularidade, reconhecido os efeitos que os deslocamentos significantes podem operar no interlocutor.

Podemos dizer, portanto, que ao fazer rolar a equivocidade da língua, participa ativamente na/da construção de sua subjetividade. L. visita o campo do Outro, colhe seus significantes, cola-se a eles, depois se safa disso. (RIOLFI, 2003, p. 233)

No presente trabalho na análise do material selecionado, procurarei pensar as mudanças de posição da criança na relação com o outro e a escrita, identificando nos textos apresentados as marcas das posições sugeridas por De Lemos.

\footnotetext{
${ }^{5}$ Segundo o autor, a noção de autoria está intimamente ligada a possibilidade de reconhecimento e punição/ aprovação daquele que escreveu, dado que o texto historicamente passa de um estatuto de ato para o estatuto de produto social. Para que haja um autor é necessário que se conheça em parte as condições de produção do discurso, que se conheça um ser que se responsabilize por aquilo que escreve e que sua escrita seja um produto de operações complexas em que a singularidade se inscreve nas regras.
} 


\section{A criança escreve}

\section{O menino que carregava água na peneira}

Tenho um livro sobre águas e meninos

Gostei mais de um menino que carregava água na peneira.

A mãe disse que carregar água na peneira

Era o mesmo que roubar um vento

e sair correndo com ele para mostrar aos irmãos.

A mãe disse que era o mesmo que catar espinhos na água

O mesmo que criar peixes no bolso.

O menino era ligado em despropósitos.

Quis montar os alicerces de uma casa sobre orvalhos.

A mãe reparou que o menino

Gostava mais do vazio do que do cheio.

Falava que os vazios são maiores e até infinitos.

Com o tempo aquele menino

Que era cismado e esquisito

Porque gostava de carregar água na peneira

Com o tempo descobriu que escrever

seria o mesmo que carregar água na peneira.

No escrever o menino viu que era capaz de ser noviça,

monge ou mendigo ao mesmo tempo.

O menino aprendeu a usar as palavras.

Viu que podia fazer peraltagens com as palavras.

E começou a fazer peraltagens.

Foi capaz de interromper o vôo de um pássaro

botando ponto no final da frase.

Foi capaz de modificar a tarde

botando uma chuva nela.

O menino fazia prodígios.

Até fez uma pedra dar flor!

A mãe reparava o menino com ternura.

A mãe falou:

Meu filho você vai ser poeta.

Você vai carregar água na peneira a vida toda. 
Você vai encher os vazios com as suas peraltagens

E algumas pessoas

Vão te amar por seus despropósitos.

(BARROS, 1999)

O exercício de investigação dos textos apresentados a seguir ensaia uma aproximação à escrita da criança, o que pode ser útil nas reflexões e nas práticas pedagógicas e no campo fonoaudiológico.

Os dados apresentados a seguir são produções escritas pela mesma criança, um menino, em momentos cronológicos e condições de produção diferentes. Trata-se de quatro produções as quais serão discriminadas como texto 1, 2, 3 e 4 e seguem anexas ao presente texto. A criança produziu os textos entre 6,4 e 7,8 anos. Os textos foram selecionados ao acaso, de modo que não se buscou uma regularidade entre tempo (intervalo) de produção ou condições de produção dos textos.

Para entender para que outro escreve a criança, trago aqui algumas observações que podem ser feitas a partir do material produzido; a análise que realizo não segue qualquer modelo formalizado, mas procura buscar indícios das relações entre a criança, a escrita e o outro. Não são textos representativos ou que fundamentem um argumento, mas meu caminho aqui é oposto: justamente procurar no texto cotidiano, comum, possibilidades de leitura.

Os textos da criança estão inseridos no corpo do presente trabalho, mas seguem também em anexo, para melhor visualização e leitura.

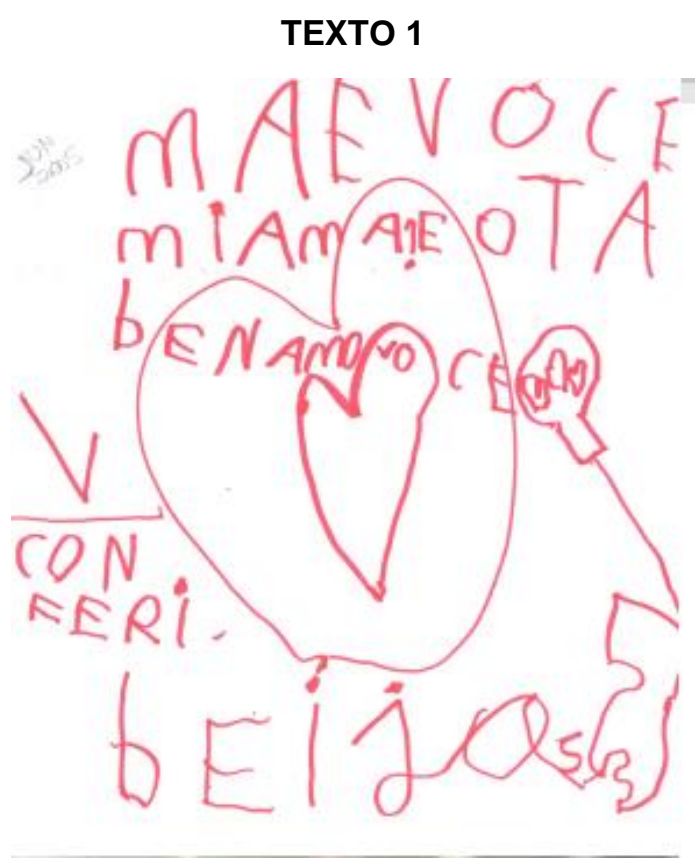


O texto foi entregue pela criança à mãe, como uma carta; foi produzido aos 6 anos e 6 meses; foi realizado espontaneamente (sem solicitação de adulto) na casa da criança, em um papel qualquer (normalmente papéis de rascunho que ficavam à disposição da criança para desenhos etc.). Podemos observar:

- É possível perceber que desenho e escrita formam um complexo semiótico; não há separação entre texto e imagem;

- A letra utilizada é a letra bastão, com elementos da cursiva, enquanto na escola a criança estava sendo alfabetizada com a letra cursiva;

- O uso de $1^{\text {a }}$ pessoa, marca o locutor; o destinatário também está marcado no texto, configurando o gênero discursivo de carta ou bilhete; o destinatário da carta coincide com o endereçamento do material escrito: a carta foi escrita para a mãe, e a criança deu a ler à mãe;

- Aparece uma marca interessante : "conferi" que era usado pela criança em toda a produção escrita na época ; é difícil precisar de onde a criança tomou esta marca gráfica, mas era usada quase como um carimbo, uma assinatura; embora a criança não conferisse realmente o material escrito, esta marca pode ser lida como índice da diferenciação entre aquele que escreve e aquele que confere, ou lê o que escreveu ; há um outro leitor suposto, um índice de alteridade na constituição da escrita;

- A criança não se corrige ao escrever, mas é possível observar erros que podem indiciar um trabalho na língua, como nos casos eu/eo , me/mi;

\section{TEXTO 2}

O texto 2 foi enviado pelo correio ao primo de 4 anos que viva, na ocasião, fora do Brasil. A carta foi produzida aos 6 anos 4 meses, na casa da criança, em papel especialmente discriminado para a atividade; sua produção foi motivada por uma carta recebida e pelo estímulo de adultos para que a criança respondesse. 


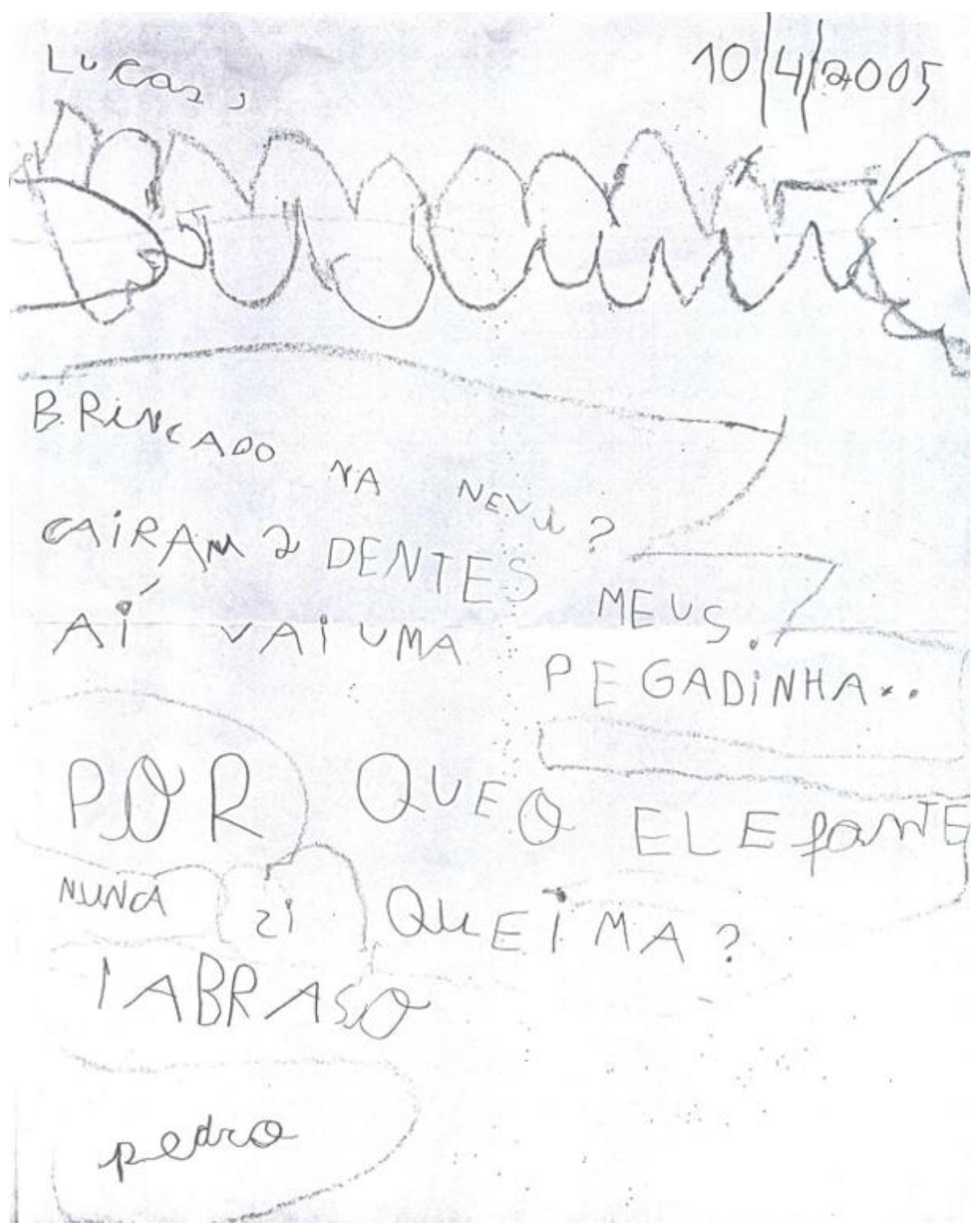

- Há uma dupla solicitação pela escrita da criança: o primo que escreve a carta e os familiares que incentivam a criança a responder a carta;

- Observa-se a organização formal característica do gênero carta; a criança tinha em mãos a carta que recebera do primo e observou detalhes como marcação de data, destinatário e remetente;

- O material escrito tem um destinatário claro, o primo que mora longe, mas a criança deu a carta para que a mãe lesse e em seguida para o pai e a avó;

- O texto escrito e as imagens apresentam-se misturados, as imagens parecem fazer bordas e molduras nas palavras e não há desenhos com significados claros;

- O conteúdo da escrita corresponde ao esperado em uma carta: comentário a respeito da carta recebida, relato de novidades, mas a 
criança termina a carta com uma charada, que embora não seja muito comum em cartas, engata o outro em uma resposta;

- Ocorre uma mistura de letra cursiva e bastão;

\section{TEXTO 3}

O texto 3 foi produzido aos 7, 2 anos, em um papel qualquer, e representava a escrita de um plano que a criança desenvolvia para provocar a irmã mais nova; foi produzido espontaneamente, em casa; não foi endereçado a qualquer adulto, mas quando foi encontrado pela mãe a criança localizou-o como parte de "documentos secretos", mas não se opôs que fosse lido.

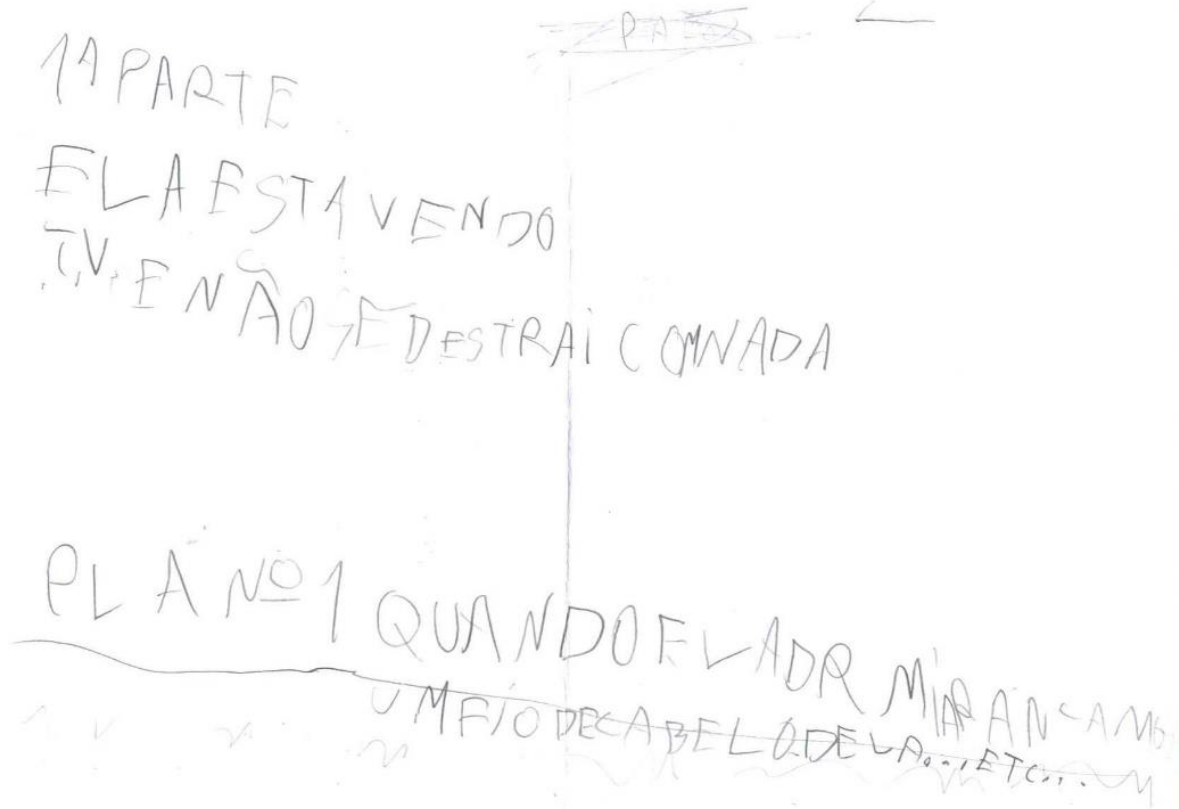

- A produção do texto é espontânea; não há solicitação por parte de adulto ou outra pessoa para que a criança escreva;

- Não há desenhos ou ilustrações;

- Uso exclusivo de letra bastão, enquanto na escola se usa cursiva;

- Não preocupação com formatação ou gênero; trata-se da anotação de um plano, cujo virtual leitor pode coincidir ou não com aquele que escreve;

- O endereçamento revela uma instância outra que não um outro semelhante;

- Embora o texto não tenha sido entregue para alguém lê-lo há de certa forma uma sedução pelo escrito, já que a criança permite a leitura do segredo pelo outro e de certa forma justifica ou tenta redimir , sabendo do valor que o outro dá à atividade de escrita, a pena pelo conteúdo e intenções manifestas no texto. 


\section{Texto 4}

O texto 4 foi produzido aos 7 anos e 8 meses, na escola, sob solicitação da professora a todos os alunos da classe, em uma situação de avaliação não formalizada.

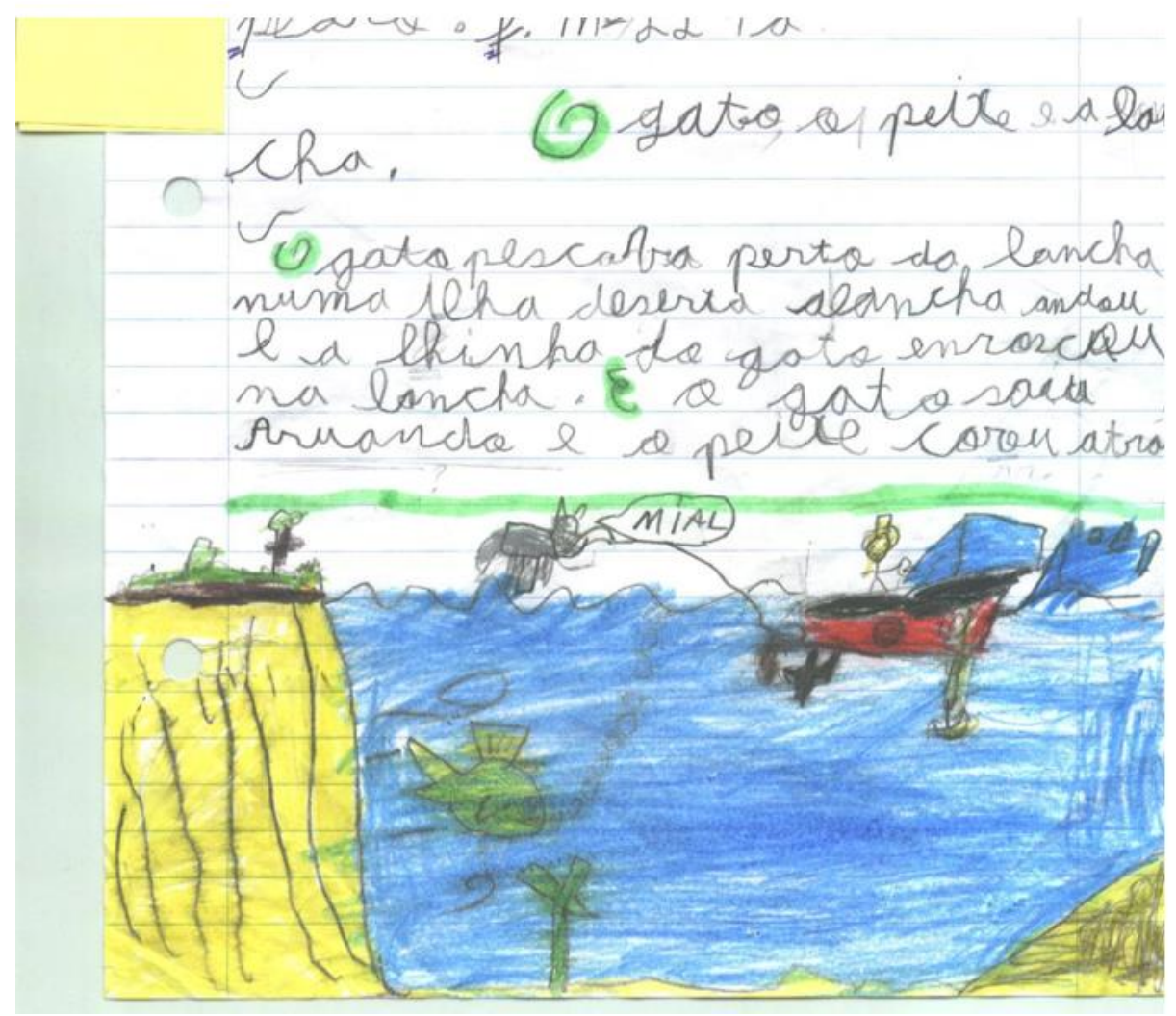

- Há solicitação específica para a produção do texto: a professora pede e há penas (a criança sabe que está sendo avaliada);

- A letra usada é exclusivamente cursiva;

- Há separação clara entre texto escrito e desenho e os desenhos tratam de ilustrar o texto;

- É possível perceber preocupação com aspectos formais da escrita: cabeçalho, data, nome da criança, uso de maiúsculas, definição de título;

- O gênero é claro: narrativa, com contextualização de cenário e personagens, ação e desfecho;

- O destinatário é a professora, mas o texto é escrito para um leitor qualquer e não apenas a professora;

A partir das observações expostas é possível tecer comentários que articulam o material analisado à teoria apresentada no início deste trabalho. 
Uma primeira observação se faz necessária: é evidente que quando a criança inicia sua entrada na escrita ela já experimentou, na linguagem oral, diferentes momentos em que tenha se colocado nas três posições descritas por De Lemos. Assim é possível imaginar que na escrita a criança possa assumir uma ou outra posição (inclusive em um mesmo texto), sem esperar que haja uma progressão temporal, em etapas, mesmo porque, ao pensarmos em etapas estamos nos referindo a uma concepção desenvolvimentista na relação da criança com a linguagem, que não é a concepção adotada aqui nesta análise.

Nos textos 1 e 3 , que são " livres" , a criança usa a letra que quer e parece mais capturada pelo movimento da escrita, do que alienada no discurso do outro ou preocupada com adequar suas preferências às exigências da escrita formal; no texto 2 as condições de produção são muito particulares : a criança é de certa forma exigida a escrever, embora em casa, sem cobrança de tipo de letras ou certo/errado que pode aparecer na escola: estas condições são expressas na escrita da criança que usa um curioso misto de cursiva/bastão e uma forma particular de emoldurar as palavras; há uma tentativa de amarrar as palavras ao campo do outro, mas um enigma, uma pegadinha, alivia este amarramento e evidencia uma atenção por parte da criança no funcionamento da língua.

No texto 4 é clara um posicionamento subjetivado ao campo do outro, mas ao mesmo tempo marcado pela singularidade. Em um contexto formal e socialmente estruturado, há um evidente traço de subversão à regra, expressa pela narrativa: o peixe que "voa" atrás do gato!

É interessante apontar que a criança escreve quando solicitada explicitamente ou espontaneamente. Isso não significa que quando não há uma solicitação de produção não haja uma demanda por parte do outro. O espaço de falta criado na relação com o outro e a possibilidade de deixar que criança procure preencher este espaço, muitas e muitas vezes possibilita que o Outro vá tomando forma, forjando um sujeito que se inscreve e a criança escreve.

Nota-se que os textos se apresentam com algum tipo de pergunta ou mistério, algo não está claro ou está fora de lugar. O que é exatamente o "conferi" do texto 1? Quem é o destinatário do texto 3 ? A pegadinha do texto 2 e a brincadeira do texto 4 fazem lembrar que escrever e ler é cifrara decifrar, inventar, colocar marcas da alteridade dentro do escrito. Belintane (2006) nos lembra que as adivinhas e brincadeiras orais da criança podem fazer apresentar movimentos da subjetividade em relação à língua e à entrada na leitura/escrita.

Nos textos analisados não é possível identificar apenas uma posição subjetiva assumida pela criança na relação com o outro e a escrita, mas momentos em que estas posições se manifestam no mesmo texto; a criança já experimentou na fala a alienação a fala do outro e a necessidade de interpretação e por vezes esta posição se manifesta na escrita; a criança já esteve às voltas com os movimentos da língua e estes movimentos são 
atualizados na escrita ; assim, movimentando-se em diferentes posições a criança vai esboçando sua autoria, diferentes modos de se pôr na escrita: ora escreve para um outro encarnado, semelhante, ora para o outro próximo, a mãe, ora para um outro que é socialmente constituído e estes diferentes endereçamentos vão possibilitando à criança se assujeitar à Língua às regras do escrever e ao mesmo tempo achar as brechas possíveis para transgredir e exercitar o pequeno autor, e como disse Manoel de Barros, preencher vazios com peraltagens.

Embora não seja objeto deste artigo, é interessante apontar para o processo de perda do corpo, da imagem, no decorrer da formação do pequeno escritor: assim como ao falar o gesto e a movimentação corporal perdem força para focalizar a palavra, no texto escrito, o amálgama semiótico imagem/letra dá lugar a uma progressiva separação e valorização das letras.

Pensar a escrita como prática de linguagem e considerar a enunciação, os índices de alteridade e o endereçamento presentes no texto, pode ser útil para melhor compreender o complexo processo da apropriação da escrita pela criança.

\section{REFERÊNCIAS}

BELINTANE, C. Subjetividades renitentes entre o oral e o escrito. In REZENDE, N.L. ; RIOLFI, C.R. SEMEGHINI-SIQUEIRA, I . Linguagem e Educação - Implicações, técnicas, éticas e estéticas. São Paulo Associação Editorial Humanitas, 2006

BENVENISTE E. Problemas de linguística geral. São Paulo, Companhia Editora Nacional da Universidade de São Paulo, Editora, 1976

BOSCO, R.Z. No jogo dos significantes, a infância da letra. Tese de doutorado. Campinas, UNICAMP, 1999

DE LEMOS, C.T.G. "Das vicissitudes da fala da criança e de sua investigação". Cad. Est. Lin. Campinas (42): 41-69, Jan/Jun 2002

FOUCAULT, M O que é um autor? Lisboa: Passagens, (1969/1992)

LACAN, J. Subversão do sujeito e dialética do desejo no inconsciente freudiano in Escritos, Rio de Janeiro, Jorge Zahar Editor, 1998.

NAZAR, T. "O escrito da escrita" - in MARIANI, B. A escrita e os escritos: reflexões em análise do discurso e psicanálise. São Carlos: Editora Claraluz, 2006.

RIOLFI, C. R. Equívoco e singularidade: subjetividade na fala de uma criança. In PASCHOAL LIMA, R.C. C. Leitura; múltiplos olhares. Campinas, Mercado das letras. 